\title{
Development Pattern Research on Urban and Rural Transportation Resources Integration
}

\author{
Yiming Zhou ${ }^{1, \text { a }}$, Qingge Pang ${ }^{2, b}$ \\ ${ }^{1}$ China academy of transportation sciences, Beijing, 100029, China; \\ ${ }^{2}$ China academy of transportation sciences, Beijing, 100029, China. \\ a30959709@qq.com, b55734906@qq.com
}

\begin{abstract}
The development on urban and rural transportation resources Integration is the new trend in urban and rural transportation supporting economic and social developments; it is also the important way in promoting urban and rural public service equalization. This paper analyzes and studies 5 development patterns on urban and rural transportation resources Integration that including: passenger and freight alliance, transport and mail cooperation, transport and trade coordination, transport and agriculture progress, Integration electronic commerce win-win, which offers pattern references for every place conducting urban and rural transportation resources Integration.
\end{abstract}

Keywords: Urban and rural transportation, resources Integration, development pattern.

\section{Outline}

The development on urban and rural transportation resources Integration is the new mechanism which is according to cross-department to construct and manage, and cross-sector to cooperate and develop. By making full use of management and resources advantages of various departments such as transport logistics, commerce, supply and marketing, postal et al. After the integration and share of resources, optimization of allocation, it achieves the integration and development of transportation and other industries to the maximum extent, which forms a new development model titled "a point more power, a net more appliance, depth fusion, cooperation and sharing" on urban and rural transportation.

\section{Analysis of Model Development on Urban and Rural Transportation Resources Integration}

\subsection{Model of Passenger and Freight Alliance.}

Logistics enterprises can make full use of density advantages of passenger transport network and freight route advantages of across the own province to build regional dedicated line alliance and logistics integrated delivery network. Meanwhile, it also can take advantage of the village to village accessibility resource of urban and rural passenger regular bus to undertake distribution business of small items. The center of transportation logistics distribution is established in county passenger transport center, the advantages of urban and rural passenger regular bus are utilized to carry out the deliver work that are small express delivery and small distribution goods in the whole villages and towns. In terms of small and time limited cargos, passenger cars are applied in fixing time, point and line to deliver cargos to logistics distribution places in rural country every day. In terms of big items and vehicle objects, freight route of logistics enterprises can be used to deliver items to logistics distribution places in rural country. The cargos which are needed to load and return can be delivered to logistics parks. According to delivery direction of cargos, logistics parks dispatch regional distribution in whole route and transport across the province to ensure the small, time limited and vehicle objects to arrive safely and in time.

\subsection{Model of Transport and Mail Cooperation.}

The development on urban and rural logistics can make full use of the network advantages of post service and carry out the cooperation of the integration and development on urban and rural logistics 
actively with the postal department. Urban and rural logistics and passenger regular buses can be applied to posts instead. Urban and rural logistics enterprises can take the source of goods on sites that are logistics parks and integrated logistics service station in rural to postal department to transport, which can expand the scale of operation, save the transport costs and improve the economic benefits each other. Transport logistics and postal services exert the advantages on their own to achieve complementary advantages and win-win developments.

Taking passenger terminal all over the rural as the center to build integrated service station of transport and mail cooperation, poster department dispatches service personnel into passenger terminal. The stations of original postal service are canceled and all business and staff apart from postal saving are dispatched to passenger terminal, which can undertake passenger transportation services, postal delivery, agricultural trading et al. service programs together in rural.

The installment of integrated service station takes village halls, stores in the center of the village and other villagers centralized places as the main target. Post office takes charge of integrated service station to be rebuilt and invests the necessary facilities and equipment of postal service. Transport department invests the facilities and equipment of waiting lounge.

Transport contractual relationship is built with rural passenger regular bus, by which take the mail, express delivery and parcels along the villages route to integrated service station in rural.

The model of cooperation and creation forms the integration of resources and complementary advantages, which can serve the people conveniently, achieve win-win situation of the transportation, post, operators, farmers, improve happiness index of farmers and serve the three issues of agriculture, countryside and farmers better. After the transport and mail cooperation starts, famers are able to pay the telephone fee in rural as well as water fee and cable television fee and so on. Farmers can go shopping by internet in rural instead of getting express delivery in villages and towns by the transport and mail cooperation, which is fast and convenient. Furthermore, it also can draw and save money at home. When people wait and take the passenger regular buses, you can set the post office as a passenger sub-station or stops, which can provide a waiting position of shelter.

\subsection{Model of Transport and Trade Coordination.}

Agricultural products delivery network is constructed. The transportation departments can help logistics companies, supermarkets and commercial enterprises to establish cooperative relations, which make the logistic enterprises rely on road transportation and advantage of regional distribution to provide the service of city material distribution for the commercial enterprises, to offer the transport service of green vegetables, water products and agricultural products for the supermarket, to supply the green vegetables for the school, hospital, company, canteen and hotel. As a result, it reduces overall logistics costs and accelerates the velocity of circulation of agricultural products.

\subsection{Promoting Transport and Agriculture Progress.}

Rural and urban market is constructed and delivery network is purchased. Logistics enterprises need to strengthen exchanges with agricultural production, industrial base and vegetable base to collect the logistics information, and promote the cooperation of logistics enterprises and businessmen. By the situation of building a win-win cooperation and joint cooperation, based on supermarket chains, sales in rural, agricultural production, processing and sales units, integrating the postal logistics and trade supplying system power expend the logistics scale in rural. Meanwhile, Occupation of logistics market is improved. Logistics enterprises can hand in rural store and open the lines of freight in village to complete the freight transportation service in time, to provide the convenient service for the farmers, to increase profit point for the stores in village.

\subsection{Model of Integration Electronic Commerce Win-win.}

The development on urban and rural logistics can make full use of the network advantages of post service a Development on urban and rural logistics can be combined with electronic commerce. Using "internet + urban distribution+ rural logistics Integrated two-way interactions" model, relying on urban and rural logistics e-commerce platform and perfect logistics system develop the urban and 
rural electricity supplier logistics network titled that "the core of distribution center, the point of distribution base, the line of electric e-commerce platform and logistics".

Rural logistics e-commerce platform which meets local condition is created with electricity supplier team. It can provide the transaction, credit, finance, billing, information and other services. The data of logistics trading, supply structure, flow distribution, car source structure is analyzed by the platform to offer personalized service for the client, which can achieve the application of Intelligent equipment, mobile communications and other technical equipment.

By integrating supply and marketing service website, delivery company land shunt business and trading distribution system, efficient distribution of the express delivery, agricultural and consumer goods can be achieved. The pace of development whose rural electricity supplier speed up. Based on rural and urban logistics e-commerce platform, information network building is accelerated. People should make efforts to establish a wider range of network information and a network station in big and rural areas, which could achieve the real-time tracking for the product, enterprise products, all kinds of rural living materials and various aspects of logistics. Resource sharing and development can come true by linking enterprises and rural service website. Combing the various resources of supply and marketing network, postal distribution outlets, food processing enterprise and farm shop named "Ten Thousand Villages Market Engineering", urban and rural transportation logistics activities could be vigorously launched to further expand the coverage of urban and rural transportation logistics network.

Warehousing management information system is set up, which can use sensing technology of twodimensional code and radio frequency identification (RFID) to get on order operations, cargo management and customer service. Automation equipment can be equipped with sorting, transmission, identification, monitoring, navigation and positioning. Cargo handling and transportation equipment of high-performance should also be assembled.

Through the e-commerce platform and vehicle scheduling platform, system scheduling of cargos and vehicles can be operational. Rural distribution base and village-level distribution point of the layout is applied to solve the logistics delivery problem of "the last mile". Online links of distribution center, rural distribution base and village - level distribution points could be coming true as well as the cooperation of the chain of commercial outlets, large office building, enterprise and educational institutions et al. Terminal distribution station and intelligent self-help delivery container is set up in the distribution base to pick up in website store and consolidate end-of-distribution resources.

\section{Conclusion}

Considering that everyplace have different situations, development mode should also be adapted to local conditions. Every departments and industries are based on their own duty to integrate and develop, arrange related resources, reduce the waste of resources, which can actively provide strong support for the local economic and social development in rural and urban areas.

\section{References}

[1]. PH Ketikidis, Philip T. Evers, Martin E. Dresner. Analyzing private communities on Internetbased collaborative transportation networks. Elsevier, (2008) p.23.

[2]. Jayanth Jayaram, Keah-Choon Tan. Supply chain integration with third-party logistics providers. Elsevier, (2010) No. 125, p.263.

[3]. Parsons-clough Harbour. Co-ordination and integration mechanisms to manage logistics processes across supply networks. Journal of Purchasing \& Supply Management, (2004) No.09, p.121. 